\title{
Promoting Participation in DCD: Physical Activity Levels and the Social Network
}

\author{
Bert Steenbergen $^{1,2} \cdot$ Hidde Bekhuis $^{3} \cdot$ Femke van Abswoude $^{1}$
}

Published online: 26 April 2020

(C) The Author(s) 2020

\begin{abstract}
Purpose of Review Physical inactivity is a worldwide problem, also affecting children with motor problems, such as developmental coordination disorder. We try to understand what motivates children to start, continue, and stop having an active lifestyle and explore the role that the social network of the child can have to stimulate an active lifestyle.

Recent Findings Social network theory is useful for understanding individual and group behavior related to physical activity. Social networks, ranging from peers and parents to teachers and medical professionals were shown to play an important role in bringing about sustainable behavioral change. Up to now, little systematic research has been done into how social networks can be used to keep children with developmental coordination disorder (DCD) physically active and motivated.

Summary Future studies should more systematically examine and target the social network of the child with DCD. This social network can then be used to develop interventions for a sustained physical active lifestyle leading to increased participation in the society.
\end{abstract}

Keywords Developmental coordination disorder $\cdot$ Participation $\cdot$ Physical activity $\cdot$ Social network

\section{Introduction: the Rise of Inactivity}

Physical inactivity is a pressing, persistent, and worldwide problem, currently identified as the world's leading factor for all-cause mortality. The detrimental consequences of an inactive lifestyle were, for example, convincingly shown in the strong association between physical inactivity and noncommunicable diseases, such as type 2 diabetes and cardiovascular disease, and the association with social problems [1, 2]. On top of that, the relation between physical inactivity and

This article is part of the Topical Collection on Motor Disorders

Bert Steenbergen

steenbergen@pwo.ru.nl

1 Behavioural Science Institute (BSI), Radboud University, Nijmegen, The Netherlands

2 Centre for Disability and Development Research (CeDDR), School of Behavioural and Health Sciences, Australian Catholic University, Melbourne, VIC, Australia

3 Radboud Social Cultural Research (RCSR), Radboud University, Nijmegen, The Netherlands obesity and obesity-related chronic diseases in children is well documented as a serious public health problem [3••].

Despite numerous interventions and initiatives, the problem of physical inactivity has not disappeared. Quite on the contrary, individuals have become increasingly inactive, especially starting from young adulthood. This inactivity affects all age groups and is present in all socio-economic levels. An inactive lifestyle relates to both a lack of involvement in sports activities and a lack of leisure time physical activities, as well as to sedentary behavior at work, in schools, and at home. Inactive lifestyle patterns are known to contribute to increasing health issues, decreased participation in society, work disability, and social isolation [4]. Conversely and importantly, an active lifestyle holds a significant role in the society, and it fulfills several functions, ranging from health improvement to the growth of social networks and social capital $[5,6]$.

Given the overwhelmingly advantageous values attached to physical activity and its role in improving lifestyle patterns, it is critical to understand what motivates people to start, continue, and stop having an active lifestyle. Having an active lifestyle includes participation in sports and exercise, but can also relate to physical activities that are incidental to daily living like commuting to work by foot or bike. Although several studies have eloquently demonstrated the value of active 
lifestyle, research on the facets that stimulate people to take part in sports and exercise and remain connected to it is very limited. This is especially pressing for individuals from vulnerable social groups, like low SES or individuals with a physical disability who score low on active behavior and fail to comply with the norm of weekly physical activity $[3 \cdot \bullet, 7,8$, 9] as recommended by the World Health Organization [10].

Inactivity is even more prominent in children who have difficulties with the learning and performance of motor skills, such as children that are diagnosed with developmental coordination disorder [11]. Several studies have shown that these children have reduced exercise tolerance and physical activity levels, a situation that persists into adulthood [12]. In turn, less frequent and less diverse participation in activities of daily living is observed, in particular in those activities that involve physical activity $[13 \cdot, 14]$, either alone or together with peers. This is known to be associated with low competence, confidence, and knowledge about physical activity, which together form the concept of physical literacy [15]. The concept of physical literacy is a feasible framework from which proficiency of motor function and participation in motor activities can be scrutinized and understood. Still, it awaits systematic empirical testing in the field [16].

\section{Children with Developmental Coordination Disorder and Physical Activity}

Developmental coordination disorder (DCD) is not a trivial disorder, with between 5 and $10 \%$ of all school-aged children experiencing motor difficulties [11]. The number of scientific studies of DCD has accelerated over the past decade leading to important new insights about the antecedents and consequences of poor motor coordination [17], the direct effect of the environment on their activity performance and participation [18••], and approaches to intervention that are most promising for longer term change in performance and behavior [19••]. We will use the collective insights from these studies to promote (sustained) physical activity and increased participation in this group of children. Specifically, we will adopt an integrative approach to theory development and praxis, referencing knowledge from fields other than motor development (notably, social network theory, [20••]) which enable a broader socio-ecological perspective on activity behavior, participation in society, and life satisfaction.

By definition, the impairment in movement skill development in children with DCD is such that it interferes with the child's ability to engage in sport and physical recreation activities. In its totality, DCD presents a significant obstacle to participation in leisure activities per se. In particular, these children are less likely than their typically developing peers to participate in free-play activities or in organized play, such as team sports $[21 \bullet, 22]$. Children with motor skill difficulties, as young as 4-6 years, engage less in mature gross and fine motor play than their typically developing peers and, over time, generally participate less in free-play, individual leisure activities, or organized activities $[21 \bullet, 23]$. In general, children with DCD are more likely to select sedentary activities and are less likely to enjoy physical education classes, leisure, and other activities [22]. Importantly, in boys, the gap in participation in free-play activities between those with and without DCD may diminish with age, but it increases for girls [21•]. In a recent study, it was highlighted that in children with probable DCD, there may be an antecedent [24]. These children are not yet recognized as having an activity deficit, which may in fact be shadowed by the relatively low motor skill demands of play in this age group. Therefore, it is important that early motor interventions promote continued physical activity participation in children with (probable) DCD.

What are the known ingredients for sustained active living and the psychosocial and environmental factors that are related to participation? With respect to the latter, our main point of reference is the family of participation-related constructs (fPRC) that was recently proposed by Imms and colleagues $[25 \bullet \cdot$. We will integrate a social network approach, as well, to better understand the range of social factors that influence active living in children with DCD and help sustain positive lifestyle patterns. Children with DCD are known to have much lower activity levels compared with their peers, and they are less physically active and less physically fit [14]. In particular, the coordination of complex movements such as those required in active play and sport activities are problematic for children with DCD [21•]. This is then reflected in low participation rates in organized sports, exacerbated by limitations in knowledge about how to integrate such children into a team environment where they feel safe and accepted [13॰]. A sobering consequence of reduced physical activity is further delayed in the acquisition of motor skills, including those necessary for daily living. The net result is a (negative) cyclical pattern of impairment in activity, participation in life activities, and movement skill.

\section{Children with Developmental Coordination Disorder and Participation}

Participation is considered a vital component of healthy living and well-being in children both with and without disabilities, and provides an important context for learning and well-being [26], and is embodied as one of the key features in the International Classification of Functioning, Disability and Health: Children and Youth (ICF-CY) Version of the World Health Organization [27]. In the ICF-CY, participation is defined as a person's "involvement in a life situation"- a societal-level of functioning. Because of their motor learning difficulties and restrictions, children with DCD are known to 
have reduced levels of participation and associated issues with self-esteem and self-efficacy [28].

Supervision of children with motor difficulties such as cerebral palsy during sports has been identified as a crucial factor to stimulate these children's participation in sports activities [29]. In this respect, we recently showed that pediatric physical therapists can play an important role in promoting sports participation of children with DCD in the Netherlands [13•]. In this study, a combination of questionnaires as well as in-depth interviews was administered to pediatric physical therapists. The content was related to the guidance to sports clubs that was provided by pediatrics physical therapists for the children with DCD. It was shown that pediatrics physical therapists played an important role in helping children with DCD to find an appropriate sports club, but that the participation of these children would be improved if special exercise programs would be available, and if the children's experience at the sports club would be closely monitored. This study exemplifies that significant others that surround the child's immediate environment, in the example the pediatric physical therapist, play an integral role facilitating participation, especially in early childhood. This implies that interventions aimed at promoting activity levels in children with or without motor disabilities should target their social network among other factors. Indeed, in a qualitative study, Barnett and colleagues [14] interviewed teenagers with DCD and their parents and showed the use of the multifaceted approach that is advocated here. Despite their lower levels of participation in physical activity, the children in their study indicated that they enjoyed many physical activities. Next to individual factors such as poor motor skill, lack of motivation, and easy fatigue, there were factors related to environmental constraints such as travel, lack of support from peers and lack of teachers' knowledge of DCD, and even lack of family engagement in the child's activities.

\section{Using the Social Network to Improve Participation in Children with Developmental Coordination Disorder}

In order to best conceptualize the range of social, environmental, and individual factors that facilitate and predict participation, we use the recently developed "family of participation related constructs [fPRC]" model [25••]. This framework was developed based on a series of systematic reviews of research in the field of childhood disability. Important aspects of the model are the environment and the context, which is more specific compared with the environment and relates to places, people, objects, activity, and time. It is particular in this sphere of influence, where the present paper has its focus on. In particular, we focus on "People," which means the social network surrounding the individual as a lever to improve participation. The social network surrounding a person is crucial for sustainable participation as was shown by the abovementioned examples [13•, 14]. In fact, having a child move from a "non-participant" to a "participant" necessitates a behavioral change. Existing scientific studies on behavioral change have shown a remarkable "blind spot": the crucial role of a social network formed by partners, peers, and close others. Generally, there exists a tendency to ignore or underestimate the strength of the context (thus, the social network) and to focus only on individual factors contributing to behavioral change. However, social networks, either offline or online, can play an important role in bringing about sustainable behavioral changes $[30,31]$. The social network-ranging from peers and parents to employees, teachers, and medical professionals - can facilitate specific behaviors by modeling the desired actions, doing activities together, or by simply encouraging desired behavior. On the other hand, undesirable behavior can be punished by evidence of disapproval, loss of status and prestige, or, in the most extreme case, exclusion $[30,32-34]$. It is hypothesized that significant others also affect a person's pattern of physical activity, that is, social network contacts may encourage, but also discourage sport participation and being physically active. In general, reviews have stressed the importance of peers for physical activity of adults and children. As an example, Salvy and colleagues [35] showed that children, when in the company of a friend, biked a larger distance than when biking alone.

Social network theory is useful for understanding individual and group behavior related to physical activity [20•0], in particular, because it acknowledges that individuals are embedded in a social context that affects their behavior, hence behavioral change. Examining the interrelatedness of the social structures is predominantly performed via social network analysis, consisting of sociograms that represent the actors and their relationships. Subsequently, this social network analysis can be used as departure point for social network interventions. It is beyond the scope of this paper to provide a detailed description of the stages of these social network analyses and social network interventions, but important for the present argument is that persons in someone's social network are crucial influencers for the individual, the so-called influence agents $[20 \bullet \cdot]$. In the example provided above, the pediatric physical therapist was identified as a crucial person in the social network of the child to promote sports participation of that particular child [13•]. As "intervention," the therapist subsequently went to the sports club together with the child, thereby creating a situation in which the child was more likely to start and continue physical activity behavior.

Apart from focusing on the "modelling" of influence agents who were identified following the social network analysis, interventions can, at the same time, be focused on the social norms within the social network. For example, if children observe that their peers are more physically active or 
perceive that their peers think that they should be more physically active, their own physical activity is also likely to change. It is a well-known fact that people that are similar interact more with each other than with dissimilar people [36]. Still, changing the norms of a specific group is extremely difficult to establish and likely not the best entry point for an intervention.

Although the above-mentioned potential of social networks to establish behavioral change is evident, up to now, little systematic research has been done into how social networks can be used to keep children physically active and motivated. A meta-analysis by Macdonald-Wallis et al. [37•] showed a strong positive relationship between sport participation and physical activity in children and their friends. However, the direction of causality (i.e., do people who are active get active friends, or do they become more people active through their active friends?) and the role of other actors in a social network is yet unknown. In a large cohort of children $(N=446$, mean age $=11.4$ ), van Woudenberg et al. [38] recently compared a mass media intervention with a social network intervention aimed at increasing physical activity. Although both interventions did not differ with respect to efficacy, the social network intervention increased the perceived norm toward physical activity and may therefore be more effective in the long run. In the specific case of children with DCD, we are yet to see a systematic analysis on the role of social networks for participation in physical activity.

\section{Conclusion}

Given the arguments provided above, we would advocate future studies to more systematically examine and target the social network of the child with DCD. This social network can then be used to develop interventions for a sustained physical active lifestyle. In turn, it can contribute to increased participation in the society. We speculate that the actors in the social network of children with DCD are not exactly the same as children without DCD. Therefore, a first start is to systematically map out the social network of these children including its size, diversity, agents, and influential persons. This will provide the necessary information on how, and where, to target the social network that will lead to sustained behavioral change. Evidently, this endeavor will lead to general and specific information about the effects of the social network. That is, this work in progress is likely to evolve over the time to come and will exemplify the highly dynamic nature of social network.

\section{Compliance with ethical standards}

Conflict of Interest The authors declare that they have no conflict of interest.
Human and Animal Rights and Informed Consent This article does not contain any studies with human or animal subjects performed by any of the authors.

Open Access This article is licensed under a Creative Commons Attribution 4.0 International License, which permits use, sharing, adaptation, distribution and reproduction in any medium or format, as long as you give appropriate credit to the original author(s) and the source, provide a link to the Creative Commons licence, and indicate if changes were made. The images or other third party material in this article are included in the article's Creative Commons licence, unless indicated otherwise in a credit line to the material. If material is not included in the article's Creative Commons licence and your intended use is not permitted by statutory regulation or exceeds the permitted use, you will need to obtain permission directly from the copyright holder. To view a copy of this licence, visit http://creativecommons.org/licenses/by/4.0/.

\section{References}

Papers of particular interest, published recently, have been highlighted as:

- Of importance

•. Of major importance

1. Lee IM, Shiroma EJ, Lobelo F, Puska P, Blair SN, Katzmarzyk PT. Effect of physical inactivity on major non-communicable diseases worldwide: an analysis of burden of disease and life expectancy. Lancet. 2012;380:219-29.

2. Ekelund U, Steene-Johannessen J, Brown WJ, Fagerland MW, Owen N, Powell KE, et al. Does physical activity attenuate, or even eliminate, the detrimental association of sitting time with mortality? A harmonised meta-analysis of data from more than 1 million men and women. Lancet Phys Act Ser; Lancet Sed Behav Working. 2016;388:1302-10.

3.• Sit CHP, McKenzie TL, Cerin E, Chow BC, Huang WY, Yu J. Physical activity and sedentary time among children with disabilities at school. Med Sci Sports Exer. 2017;49:292-7. This study examines the relation between physical activity and sedentary time in a large group of children $(n=259)$ with disabilities in three school settings (physical education, recess, lunchtime).

4. Coenders F, van Mensvoort C, Kraaykamp G, Breedveld K. Does sport-participation improve health? A panel analysis on the role of educational attainment, economic deprivation and work-family load. Eur J Sport Soc. 2017;14:45-59.

5. Bailey R, Cope E, Parnell D. Realising the benefit of sports and physical activity: the human capital model. Retos. 2015;28:147-54.

6. Bailey R, Hillman C, Arent S, Petipas A. Physical activity: an underestimated investment in human capital? J Phys Act Health. 2013;10:289-308.

7. Ford ES, Merritt RK, Heath GW, Powell KE, Washburn RA, Kriska A, et al. Physical activity behaviors in lower and higher socioeconomic status populations. Am J Epidemiol. 1991;133:1246-56.

8. Fröberg A, Larsson C, Berg C, Boldemann C, Raustorp A. Accelerometer-measured physical activity among adolescents in a multicultural area characterized by low socioeconomic status. Int $\mathrm{J}$ Adol Med Health. 2016. https://doi.org/10.1515/ijamh-2016-0061.

9. Seabra A, Mendonça D, Maia J, Welk G, Brustad R, Fonseca AM, et al. Gender, weight status and socioeconomic differences in psychosocial correlates of physical activity in schoolchildren. J Sci Med Sport. 2013;16:320-6. 
10. World Health Organization. Global recommendations on physical activity for health. 2010. https://apps.who.int/iris/bitstream/handle/ 10665/44399/9789241599979_eng.pdf?sequence=1. Accessed 23 Jan 2020.

11. American Psychiatric Association. Diagnostic and statistical manual of mental disorders. 5th ed. Arlington: American Psychiatric Publishing; 2013.

12. Liu F, Morris M, Hicklen L, Izadi H, Dawes H. The impact of high and low-intensity exercise in adolescents with movement impairment. PloS One. 2018. https://doi.org/10.1371/journal.pone. 0195944.

13. Adams ILJ, Broekkamp W, Wilson PH, Imms C, Overvelde A. Steenbergen B. Role of pediatric physical therapists in promoting sports participation in DCD - a mixed methods approach. Ped Phys Ther. 2018;30:106-11. This study shows the role of the social network, in this case the pediatric physical therapis, to promote participation in sports.

14. Barnett AL, Dawes H, Wilmut K. Constraints and facilitators to participation in physical activity in teenagers with developmental co-ordination disorder: an exploratory interview study. Child Care Health Dev. 2013;39:393-403.

15. Whitehead M. The concept of physical literacy. Eur J Phys Educ. 2001;6(2):127-38

16. Cairney J, Hay J, Faught B, Mandigo J, Flouris A. Developmental coordination disorder, self-efficacy toward physical activity, and play: does gender matter? Adapt Phys Act Q. 2005;22:67-82.

17. Wilson PH, Smits-Engelsman B, Caeyenberghs K, Steenbergen B, Sugden D, Clark J, et al. Cognitive and neuroimaging findings in developmental coordination disorder: new insights from a systematic review of recent research. Dev Med Child Neurol. 2017;59: 1117-29.

18.• Blank R, Barnett A, Cairney J, Green D, Kirby A, Polatajko H, et al. International clinical practice recommendations on the definition, diagnosis, assessment, intervention, and psychosocial aspects of developmental coordination disorder. Dev Med Child Neurol. 2019. https://doi.org/10.1111/dmcn.14132 This review highlights the international clinical practice recommendations for DCD.

19.•- Smits-Engelsman B, Vincon S, Blank R, Quadrado VH, Polatajko $\mathrm{H}$, Wilson P. Evaluating the evidence for motor-based interventions in developmental coordination disorder: a systematic review and meta-analysis. Res Dev Dis. 2018;74:72-102. This systematic review evaluates the evidence of current motor-based interventions for children with DCD.

20.• Valente TW. Social networks and health behavior. In: Glanz K, Rimer B, Viswanath K, editors. Health behavior: theory, research, and practice. 5th ed. San Fransisco: John Wiley \& Sons Ltd; 2015. p. 205-22. This paper provides a good description of social network theory and it use to promote health behavior.

21. Cairney J, Hay J, Veldhuizen S, Missiuna C, Faught BE. Developmental coordination disorder, sex, and activity deficit over time: a longitudinal analysis of participation trajectories in children with and without coordination difficulties. Dev Med Child Neurol. 2010;52:67-72. This longitudinal study describes participation of children over time.

22. Cairney J, Dudley D, Kwan M, Bulten R, Kriellaars D. Physical literacy, physical activity and health: toward an evidence-informed conceptual model. Sports Med. 2019;49:371-83.
23. Oudenampsen C, Holty L, Stuive I, van der Hoek F, ReindersMesselink H, Schoemaker M, et al. Relationship between participation in leisure time physical activities and aerobic fitness in children with DCD. Ped Phys Ther. 2013;25:422-9.

24. King-Dowling S, Kwan MYW, Rodriguez C, Missiuna C, Timmons BW, Cairney J. Physical activity in young children at risk for developmental coordination disorder. Dev Med Child Neurol. 2019. https://doi.org/10.1111/dmcn.14237.

25.• Imms C, Granlund M, Wilson P, Steenbergen B, Rosenbaum P, Gordon A. Participation as both a means and an end: a conceptual analysis of processes and outcomes in childhood disability. Dev Med Child Neurol. 2017;59:16-25. This study describes a conceptual model of participation, in which participation is both a means and an end.

26. Larson RW, Verma S. How children and adolescents spend time across the world: work, play, and developmental opportunities. Psych Bull. 1999;125:701-36.

27. World Health Organization. ICF-CY Version of the World Health Organization. 2007. https://apps.who.int/iris/handle/10665/43737. Accessed 23 Jan 2020.

28. Poulsen AA, Ziviani JM, Cuskelly M. General self-concept and life satisfaction for boys with differing levels of physical coordination: the role of goal orientations and leisure participation. Hum Mov Sci. 2006;25:839-60.

29. Verschuren O, Wiart L, Hermans D, Ketelaar M. Identification of facilitators and barriers to physical activity in children and adolescents with cerebral palsy. J Ped. 2012;161:488-94.

30. Bahr DB, Browning RC, Wyatt HR, Hill JO. Exploiting social networks to mitigate the obesity epidemic. Obesity. 2009;17:723-8.

31. Hinduja S, Patchin JW. Bullying beyond the schoolyard: preventing and responding to cyberbullying. 2nd ed. Thoasand Oaks: Corwin Press; 2014.

32. Callen E, Shapero D. Theory of social imitation. Phys Today. 1974;27:23.

33. Knoke D. Political networks: the structural perspective. Cambridge: Cambridge University Press; 1990.

34. Marwell G, Oliver P. The critical mass in collective action. Cambridge: Cambridge University Press; 1993.

35. Salvy SJ, Bowker JC, Roemmich JN, Romero N, Kieffer E, Paluch $\mathrm{R}$, et al. Peer influence on children's physical activity: an experience sampling study. J Ped Psychol. 2007;33:33-49.

36. Brechwald WA, Prinstein MJ. Beyond homophily: a decade of advances in understanding peer influence processes. J Res Adol. 2011:21:166-78.

37. Macdonald-Wallis K, Jago R, Sterne JA. Social network analysis of childhood and youth physical activity: a systematic review. Am J Prev Med. 2012;43:636-42. This systematic review exemplifies the use of social network analysis for physical activity in children.

38. van Woudenberg TJ, Bevelander KE, Burk WJ, Smit CR, Buijs L, Buijzen MA. Randomized controlled trial testing a social network intervention to promote physical activity among adolescents. BMC Pub Health. 2018. https://doi.org/10.1186/s12889-018-5451-4.

Publisher's Note Springer Nature remains neutral with regard to jurisdictional claims in published maps and institutional affiliations. 